\title{
OS SISTEMAS DE SAÚDE NO ÂMBITO DA UNIÃO EUROPEIA E A PRÁTICA DE TURISMO SANITÁRIO: BREVE ANÁLISE SOBRE AS REPERCUSSÕES TRAZIDAS PARA O BLOCO
}

\author{
THE EUROPEAN UNION HEALTH SYSTEMS AND THE PRACTICE OF \\ SANITARY TOURISM: BRIEF ANALYSIS ABOUT REPERCUSSIONS TO THE \\ GROUP
}

\section{SISTEMAS DE SALUD EN EL MARCO DE LA UNIÓN EUROPEA Y LA PRÁCTICA DE TURISMO SANITARIO: BREVE ANÁLISIS SOBRE LAS REPERCUSIONES TRAZIDAS PARA EL BLOQUEO}

\begin{abstract}
MANUEL FONDEVILA MARÓN
Doutor pela Universidad de La Coruna - Espanha. Professor e coordenador acadêmico do grau de ciências políticas na Universidad Internacional de La Rioja (UNIR). Espanha. http://lattes.cnpq.br/8172842430133246 / http://orcid.org/0000-0002-2462-5510 / m.fondevila.m@gmail.com
\end{abstract}

FERnANDA Dayane dos Santos QueIRoz Mestranda em Política e Instituições do Sistema de Justiça, Mestrado em Direito da Universidade Federal do Maranhão (UFMA). São Luís, Maranhão, Brasil. http://lattes.cnpq.br/5202116099480874 / http://orcid.org/0000-0003-4097-2042 / fernandadayane.queiroz@gmail.com

\begin{abstract}
RESUMO
Pretende-se com este artigo analisar se a legislação e jurisprudência europeias favorecem a prática do turismo sanitário. Parte-se do esclarecimento sobre o aparato legislativo vigente até finalmente partir de questionamentos sobre se há realmente livre circulação de pacientes, qual a repercussão social ou mesmo econômica para os Estadosmembros, como ocorre o reembolso dos gastos em saúde que sofreu amplas modificações após a Diretiva 2011/24/UE. Por fim, analisa-se a importância da existência de um sistema de cooperação em saúde na União Europeia, que hoje, pelas diferenças existentes nas regiões do referido bloco, vem ocorrendo problemas de ordem de execução, visto que alguns Estados estão mais sobrecarregados pela garantia do direito à saúde do que outros, o que evidencia a prática do turismo sanitário. Trata-se de uma pesquisa exploratória, com análise de legislação e doutrina nacional e europeia.

Palavras-chave: Direito à saúde; Livre circulação de pacientes; Reembolso dos gastos; Turismo sanitário; União Europeia.

ABSTRACT

The aim of this article is to analyze whether European legislation and jurisprudence favor the practice of health tourism. It starts on the elucidation about the current legislative apparatus until finally focusing on questioning if there is actually free movement of patients, what is the social or even economic repercussion for the member states, and how the reimbursement of health spending occurs, which had extensive modifications after Directive 2011/24/EU. Finally, it analyzes the importance of the existence of a cooperation system in health in the European Union, that today, due to differences in the regions of the group, has problems of execution, because some states are more burdened by the guarantee of the right to health than others, which evidences the practice of sanitary tourism. It is an exploratory research, with analysis of national and European legislation and literature.
\end{abstract}

Keywords: Right to health; Free movement of patients; Reimbursement of expenses; Sanitary tourism; European Union. 


\section{RESUMEN}

Se pretende con este artículo analizar si la legislación y la jurisprudencia europeas favorecen la práctica del turismo sanitario. Se parte del esclarecimiento sobre el aparato legislativo vigente hasta finalmente partir de cuestionamientos sobre si hay realmente libre circulación de pacientes, cuál es la repercusión social o incluso económica para los Estados miembros, como ocurre el reembolso de los gastos en salud que sufrió amplias modificaciones después de La Directiva 2011/24 / UE. Por último, se analiza la importancia de la existencia de un sistema de cooperación en salud en la Unión Europea, que hoy, por las diferencias existentes en las regiones de dicho bloque, se están produciendo problemas de orden de ejecución, ya que algunos Estados están más sobrecargados por la garantía del derecho a la salud que otros, lo que evidencia la práctica del turismo sanitario. Se trata de una investigación exploratoria, con análisis de legislación y doctrina nacional y europea.

Palabras clave: Derecho a la salud; Libre circulación de pacientes; Reembolso de los gastos; Turismo sanitario; Unión Europea.

\section{SUMÁRIO}

INTRODUÇÃO; 1 SISTEMAS DE SAÚDE DA UNIÃO EUROPEIA; 1.1 Legislação; 1.2. A jurisprudência do Tribunal de Justiça Europeu; 2 UM BALANÇO ENTRE GANHOS E PERDAS DOS ESTADOS E USUÁRIOS; 2.1 "Livre" circulação de pacientes?; 2.20 reembolso dos gastos e a prestação de serviços de saúde aos usuários; 3 A IMPORTÂNCIA DA COOPERAÇÃO EM MATÉRIA DE SAÚDE NO BLOCO DA UNIÃO EUROPEIA; CONCLUSÃO; REFERÊNCIAS.

\section{INTRODUÇÃO}

O presente trabalho tem por objetivo analisar a legislação e o aparato jurisprudencial no bloco da União Europeia, a fim de observar se esses favorecem a prática do turismo sanitário. Após o estudo da legislação, de casos concretos e da doutrina, pretende-se responder se há a livre circulação de pacientes ou se a forma como se deu a cooperação em saúde na União Europeia - tendo em vista a ocorrência de problemas no momento da execução, com alguns Estados-membros mais sobrecarregados do que outros - evidenciou a prática do turismo sanitário. Busca-se ainda responder qual a repercussão social ou mesmo econômica para os Estados-membros.

Assim, surge a problemática: a configuração dos sistemas de saúde existentes na União Europeia contribui para a prática do turismo sanitário ou cumpre com o seu papel, tal como prevê a legislação, de permitir a livre circulação de pacientes para tratamentos de saúde, sem sobrecarga de nenhum Estado-membro?

Pretende-se realizar uma pesquisa qualitativa, visto que foi feita uma reflexão teóricosistemática a partir do que consta nos dados colhidos com leituras de legislação, jurisprudência e artigos sobre o tema. A vertente teórico-metodológica adotada foi a jurídico-teórica, visto que foi realizada a apresentação de aspectos conceituais, ideológicos e doutrinários sobre o tema. 
Trata-se de um trabalho exploratório de análise do aparato legislativo e de pesquisa envolvendo a doutrina.

Em um primeiro momento, buscou-se tratar da legislação da UE referente à prestação de serviços de saúde transfronteiriços, no decorrer dos anos, desde seu primeiro aparecimento, em 1970, até seu atual estágio, na vigência da Diretiva 2011/24/UE. Aborda-se também, ainda no primeiro capítulo, a importância da jurisprudência do Tribunal de Justiça da União Europeia, responsável pela ocorrência de importantes modificações ao tratar do atendimento médico nos países da União Europeia, em que as decisões tomadas ensejaram a publicação da diretiva acima mencionada.

No tópico acerca da “livre” circulação de pacientes o intuito é explanar se, após a última diretiva referente ao tema, podem ser observadas disparidades em razão da condição econômica dos pacientes do bloco. No segundo item do capítulo, traz-se o aparato normativo referente ao reembolso dos gastos, o qual passou por grandes modificações na diretiva, no sentido de que é possível (no Estado-membro que regulamentar) o reembolso integral de gastos, ainda que não seja o mesmo valor do praticado no Estado-membro de origem do paciente.

Por fim, no último capítulo, aborda-se a cooperação entre os Estados-membros para garantia dos cuidados em saúde transfronteiriços. Vê-se que a diretiva também se preocupou com a temática, pois se faz importante para a existência de assistência mútua, tanto para cuidados repressivos, quanto para a busca de tratamentos, visto que também se fala em cooperação para diagnósticos e estudos.

\section{SISTEMAS DE SAÚDE NA UNIÃO EUROPEIA}

Não cabe à União Europeia exigir que todos os Estados-membros organizem seus sistemas de saúde e de seguridade social da mesma maneira. O bloco prevê mecanismos de coordenação para evitar que os trabalhadores migrantes sofram prejuízos quando se mudam de um Estado para outro ${ }^{1}$. Atualmente, a preocupação é com todo e qualquer cidadão que reside legalmente na Europa e venha a necessitar dos serviços públicos de saúde. No presente capítulo, aborda-se a legislação e a jurisprudência pertinentes ao tema.

\footnotetext{
${ }^{1}$ CARDO, Iván Antonio Rodríguez. El fomento del turismo sanitario en la Unión Europea: la decisiva labor del tribunal de justicia. Revista de Direito do Trabalho, São Paulo: Revista dos Tribunais, v. 36, n. 137, p. 309-331, jan./mar. 2010.
} 


\subsection{Legislação}

A União Europeia (UE) possui aparato legislativo para sua atuação em prol da melhoria da saúde através das suas políticas e atividades. O Tratado de Maastricht, em seu artigo 129, estabelecia que a organização e a prestação de serviços de saúde são de responsabilidade de seus Estados-membros, mas a Comunidade Europeia devia incentivar a cooperação dos Estadosmembros e, se necessário, apoiar a sua ação. Dessa forma, o bloco contribuirá para a proteção da saúde das pessoas que nele residem, como um todo.

A Carta de Direitos Fundamentais da UE traz em seus artigos 34 e 35 direitos relacionados à prestação de saúde. 0 primeiro citado traz que a União reconhece e respeita o direito de acesso às prestações de segurança social e serviços sociais, entre esses incluída a proteção nos casos de doença, velhice e maternidade. É garantido às pessoas que residem ou se desloquem legalmente no interior da União o direito às prestações de segurança social e serviços sociais, levando-se em conta normas de direito comunitário e legislações e práticas nacionais. 0 artigo 35 trata especificamente do direito que todas as pessoas possuem de aceder à prevenção em matéria de saúde e de beneficiar-se de cuidados médicos, mantendo-se o respeito às legislações e práticas nacionais, devendo em todas as políticas e ações da União ser assegurada a proteção da saúde humana.

O Tratado sobre o Funcionamento da União Europeia (TFUE) traz em seu artigo 168, n. 1 que deve ser assegurado um elevado nível de proteção da saúde na definição e execução de todas as políticas e ações da União. A partir da leitura desse artigo ${ }^{2}$, fica evidente também que a União agirá de forma a complementar as políticas nacionais, de modo a incentivar a cooperação entre os Estados-membros a fim de aumentar a complementaridade dos seus serviços de saúde nas regiões fronteiriças.

$\mathrm{O}$ artigo 114 do TFUE também constitui a base legal da garantia do direito à saúde no âmbito da União Europeia, uma vez que a maior parte das disposições visa melhorar o funcionamento do mercado interno e a livre circulação de mercadorias, de pessoas e de serviços. A legislação da União Europeia utilizará o referido artigo mesmo quando a proteção da saúde pública seja um fator decisivo para as opções tomadas. A este respeito, o n. 3 do artigo 114 do TFUE prevê de forma expressa que, ao realizar a harmonização, deve ser garantido um elevado

\footnotetext{
${ }^{2}$ Vide artigo 168,1 . ; 2. do TFUE.
} 
nível de proteção da saúde humana, tendo nomeadamente em conta qualquer nova evolução com base científica.

$\mathrm{O}$ artigo 149 do TFUE se refere à proteção da saúde pública ao tratar que o Parlamento e o Conselho Europeu podem adotar ações de incentivo destinadas a fomentar a cooperação entre os Estados-membros e apoiando a ação dos mesmos. A União Europeia não define as políticas de saúde, nem a organização e a prestação de serviços de saúde e de cuidados médicos. A sua ação consiste em complementar as políticas nacionais e apoiar a cooperação entre Estados-membros no domínio da saúde pública ${ }^{3}$.

Trazendo um breve aparato histórico acerca do acesso aos serviços de saúde em outro Estado-membro, é importante destacar que este foi regulamentado ainda nos anos 1970 para garantir aos trabalhadores migrantes direitos de seguridade social, quando em 1971, a Comunidade Econômica Europeia (CEE) emitiu o Regulamento CEE n. 1408/71 relativo à aplicação dos regimes de seguridade social aos trabalhadores e familiares que se deslocavam no interior do mercado. Posteriormente, qualquer pessoa, mesmo que estivesse temporariamente em território dos estados europeus, passou a ter direito a utilizar os serviços de saúde para cuidados imediatamente necessários, nas mesmas condições que os cidadãos nacionais. Em seguida, foi introduzido o deslocamento para tratamento com autorização prévia, casos de atendimentos que necessitam de serviços hospitalares e aqueles que não necessitam, entre outras conquistas, que serão tratadas ainda no presente artigo.

Nesse primeiro momento, na década de 70, é importante destacar que foram criados diferentes formulários para atender diferentes beneficiários do sistema de saúde, como trabalhadores, turistas e estudantes, pois o acesso à assistência era distinto, dependendo do enquadramento nos grupos enumerados ${ }^{4}$. Esses formulários que foram criados atendiam situações específicas, como: nos casos em que havia a prestação de assistência durante estada por motivos de trabalho (E106, usuário de duplo sistema), nos casos de turismo e viagens (E111, em que garante apenas emergências), na busca de emprego (E119), para estudantes e trabalhadores enviados a outro país (E128), no caso de autorizar viagem para tratamento médico pré-definido por motivos específicos de falta ou dificuldade de prestação do serviço, tais como

\footnotetext{
${ }^{3}$ Artigo 153, 1. a) e também, nesse sentido, a diretiva 2011/24/UE, no item (7) assim preleciona: A presente diretiva respeita e não prejudica a liberdade de cada Estado-Membro decidir que tipo de cuidados de saúde considera adequado. Nenhuma disposição da presente diretiva deverá ser interpretada de molde a pôr em causa as opções éticas fundamentais dos Estados-Membros.

${ }^{4}$ GIOVANELLA, Ligia; GUIMARAES, Luisa. Integração européia e políticas de saúde: repercussões do mercado interno europeu no acesso aos serviços de saúde. Revista Cad. Saúde Pública, Rio de Janeiro, v. 22, n. 9, p. 1795-1807, set. 2006.
} 
lista de espera, acesso às novas tecnologias e proximidade geográfica (E112). Mas o turismo sanitário sob o regulamento 1408/71 tinha pequeno impacto numérico e financeiro.

Apenas em 2004 entrou em circulação o cartão europeu de seguro de doença que substituirá gradualmente os formulários "E" acima citados. 0 cartão tem como função eliminar obstáculos à mobilidade geográfica por motivo de turismo, busca de emprego e transferência de trabalho. Tem ainda função de simplificar o acesso, agilizar o reembolso e confirmar os direitos, podendo também auxiliar o alinhamento de benefícios face às competências dos Estadosmembros na organização dos sistemas de saúde.

Sobre o cartão de saúde, o Centro Europeu do Consumidor Portugal assim se refere:

O Cartão Europeu de Seguro de Doença é o documento que the permite o acesso a cuidados de saúde quando viajar num outro Estado-membro da União Europeia ou na Islândia, na Noruega, no Principado do Liechtenstein ou na Suíça. Com este cartão poderá receber assistência médica na rede de serviços públicos do país para onde viajar e após o regresso obter o reembolso de eventuais despesas que vier a suportar (taxas moderadoras ou comparticipações iguais às dos nacionais do país onde a assistência for prestada) ${ }^{5}$.

Também em 2004 entra em vigor o regulamento (CE) $n^{\circ}$ 883/2004 do Parlamento Europeu e do Conselho relativo à coordenação dos sistemas de segurança social. Esse regulamento tem o intuito de simplificar e de clarificar as regras comunitárias relativas à coordenação dos sistemas de segurança social dos Estados-membros. Com ele, os cidadãos europeus poderão mais facilmente exercer o seu direito à livre circulação europeia.

Sobre a circulação de pessoas na UE para tratamento de saúde, traz:

Artigo 20. Viagem com o objectivo de receber prestações em espécie Autorização para receber tratamento adequado fora do Estado-Membro de residência

1. Salvo disposição em contrário no presente regulamento, uma pessoa segurada que viaje para outro Estado-Membro com o objectivo de receber prestações em espécie durante a estada deve pedir autorização à instituição competente.

2. A pessoa segurada autorizada pela instituição competente a deslocar-se a outro Estado-Membro para aí receber o tratamento adequado ao seu estado, se beneficia das prestações em espécie concedidas, a cargo da instituição competente, pela instituição do lugar de estada, de acordo com as disposições da legislação por ela aplicada, como se fosse segurada de acordo com essa legislação. A autorização deve ser concedida sempre que o tratamento em questão figure entre as prestações previstas pela legislação do Estado-Membro onde $o$ interessado reside e onde esse tratamento não possa ser prestado dentro

\footnotetext{
${ }^{5}$ O Centro Europeu do Consumidor é cofinanciado pela Comissão Europeia e pela Direção-Geral do Consumidor. CENTRO Europeu Consumidor Portugal. Cuidados de saúde na União Europeia: em caso de doença ou acidente. Disponível em: http://cec.consumidor.pt/topicos1/cuidados-saude-na-ue.aspx. Acesso em: 20 jan. 2017.
} 
de um prazo clinicamente seguro, tendo em conta o seu estado de saúde actual e a evolução provável da doença.

3. Os números 1 e 2 aplicam-se, com as devidas adaptações, aos familiares da pessoa segurada 6 .

Esse artigo tem o intuito de regulamentar os casos em que o paciente viaja para receber tratamento adequado fora do Estado-membro em que reside, quando ele não pode receber o tratamento no seu país de origem dentro de um prazo seguro. Ressalta-se que, antes de se deslocar, deve ser comprovado que houve pedido de autorização à instituição competente e deve ser constatado que o tratamento se dará em outra localidade pelo fato desse não existir em tempo hábil no seu país de origem. Essas limitações são importantes para que não ocasione a realização de viagens em que o tratamento possa ser feito no país de origem do paciente e também para evitar o inchaço de pacientes em uma localidade apenas.

Em 2009 é aprovado pelo Parlamento Europeu e Conselho, o regulamento (CE) $n$. 987/2009 que tem como objetivo estabelecer as modalidades de aplicação do regulamento (CE) n. 883/2004, acima explanado. Dentre as preocupações deste regulamento, pode ser citada, conforme item (16), que:

Deverão ser clarificadas as condições de assunção das despesas relacionadas com prestações em espécie do seguro de doença no quadro de cuidados de saúde programados, ou seja, os cuidados de saúde que uma pessoa segurada vai procurar num Estado-Membro diferente daquele em que está segurada ou reside. Deverão ser especificadas as obrigações da pessoa segurada relativas ao pedido de uma autorização prévia, bem como as obrigações da instituição em relação ao doente no tocante às condições da autorização. Importa igualmente precisar as consequências para a assunção das despesas dos cuidados de saúde recebidos noutro Estado-Membro com base numa autorização ${ }^{7}$.

Traz o regulamento que os cidadãos podem receber tratamento programado em outro país da União Europeia em determinadas circunstâncias. A pessoa segurada deverá pedir uma autorização prévia de tratamento em outro país. O regulamento traz que tanto a pessoa segurada como a instituição que a recebe tem obrigações. Um exemplo, trazido no art. 25 do Regulamento (CE) $987 / 2009$, é a necessidade de que a instituição competente emita um

\footnotetext{
${ }^{6}$ UNIÃO EUROPEIA. Regulamento (CE) N. 883/2004 do Parlamento Europeu e do Conselho de 29 de Abril de 2004 relativo à coordenação dos sistemas de segurança social (Texto relevante para efeitos do EEE e para a Suíça). Disponível em: http://eur-lex.europa.eu/legalcontent/PT/TXT/PDF/?uri=CELEX:02004R0883-20140101\&from=PT. Acesso em: 23 dez. 2016.

7 UNIÃO EUROPEIA. Regulamento (CE) n. 987/2009 do Parlamento Europeu e do Conselho de 16 de Setembro de 2009 que estabelece as modalidades de aplicação do Regulamento (CE) n. 883/2004 relativo à coordenação dos sistemas de segurança social (Texto relevante para efeitos do EEE e a Suíça). Disponível em: http://eur-lex.europa.eu/legal-content/PT/TXT/PDF/?uri=CELEX:32009R0987\&from=PT. Acesso em: 23 dez. 2016.
} 
OS SISTEMAS DE SAÚDE NO ÂMBITO DA UNIÃO EUROPEIA E A PRÁTICA DE TURISMO SANITÁRIO: BREVE ANÁLISE SOBRE AS REPERCUSSÕES TRAZIDAS PARA O BLOCO

MANUEL FONDEVILA MARÓN FERNANDA DAYANE DOS SANTOS QUEIROZ

documento ao Estado-membro de estada que indique o direito do cidadão às prestações em espécie.

Há casos em que o governo realiza o pagamento de todos os custos, quando o enfermo realiza pedido ao seu organismo segurador. Mas há países em que os pacientes são transferidos, pagam os tratamentos e são posteriormente reembolsados pelo país onde foram tratados.

Na sequência, no artigo 26 do Regulamento acima mencionado, traz-se a normatização referente aos cuidados de saúde que são programados:

Art. 26 Cuidados de saúde temporários

A) Procedimento de autorização

1. Para efeitos da aplicação do n. 1 do artigo 20.0 do regulamento de base, a pessoa segurada deve apresentar à instituição do lugar de estada um documento emitido pela instituição competente. Para efeitos do presente artigo, entende-se por instituição competente a instituição que suporta os custos dos cuidados de saúde programados; nos casos a que se referem o n. 4 do artigo 20 e o n. 5 do artigo 27 do regulamento de base, em que as prestações em espécie previstas no Estado-Membro de residência são reembolsadas com base em montantes fixos, essa competência cabe à instituição do lugar de residência.

[...]

3. Se uma pessoa segurada que não resida no Estado-Membro competente necessitar de cuidados de saúde urgentes de carácter vital e a autorização não puder ser recusada, nos termos do disposto no segundo período do n. o 2 do artigo 20 do regulamento de base, a autorização é concedida pela instituição do lugar de residência em nome da instituição competente que é informada imediatamente pela instituição do Estado do lugar de residência. A instituição competente deve aceitar os diagnósticos e as opções terapêuticas relativos à necessidade de cuidados de saúde urgentes e de carácter vital dos médicos aprovados pela instituição do lugar de residência que emite a autorização. 4. Em qualquer momento do processo de concessão da autorização, a instituição competente mantém a faculdade de mandar examinar a pessoa segurada por um médico da sua escolha no Estado-Membro de estada ou de residência.

[...]

Assunção dos custos das prestações em espécie suportados pela pessoa segurada [...]

7. Se a pessoa segurada tiver efetivamente suportado, ela própria, os custos, na totalidade ou em parte, dos cuidados de saúde autorizados, e se os custos que a instituição competente é obrigada a reembolsar à instituição do lugar de estada ou à pessoa segurada, nos termos do n. o 6 (custo real), forem inferiores aos custos que teria de assumir pelos mesmos cuidados de saúde no Estado-Membro competente (custo teórico), a instituição competente deve reembolsar à pessoa segurada, a pedido desta, os custos dos cuidados de saúde suportados por essa pessoa até ao montante da diferença entre o custo teórico e o custo real. No entanto, o montante do reembolso não pode exceder o montante das despesas efetivamente suportadas pela pessoa segurada, e pode ter em conta o montante que a pessoa segurada teria que pagar se o tratamento tivesse sido efetuado no Estado-Membro competente.

C) Assunção das despesas de viagem e de estada no contexto de cuidados de saúde programados 
8. Sempre que a legislação nacional da instituição competente previr o reembolso dos custos de viagem e estada que sejam inseparáveis dos cuidados de saúde da pessoa segurada, esses custos relativos à pessoa em causa e, se necessário, a uma pessoa que tenha que a acompanhar devem ser suportados por esta instituição sempre que conceda uma autorização em caso de tratamento noutro Estado-Membro.

D) Familiares

9. Os pontos 1 a 8 aplicam-se, com as necessárias adaptações, aos familiares da pessoa segurada ${ }^{8}$.

Em 2011, foi apresentada a Diretiva 2011/24/UE do Parlamento Europeu e do Conselho relativa ao exercício dos direitos dos doentes em matéria de cuidados de saúde transfronteiriços. A diretiva deixa claro no item (4) que, embora os doentes possam receber cuidados de saúde em outros Estados-membros da UE, cada um continua responsável pela prestação de cuidados de saúde seguros, de elevada qualidade, eficazes e em quantidade suficiente aos cidadãos no respectivo território. Além disso, a aplicação da presente diretiva não deve constituir um incentivo para que os doentes efetuem tratamentos fora do Estado-membro em que reside. Dessa forma, "a presente diretiva se aplica à prestação de cuidados de saúde aos doentes, independentemente da forma como sejam organizados, prestados ou financiados"”.

Em seu artigo $4^{\circ}, 1$. , a Diretiva mostra as obrigações do Estados-membros de tratamento, quais sejam: prestar cuidados em saúde transfronteiriços nos termos da legislação do Estado-membro de tratamento; de acordo com as normas e orientações em matéria de qualidade e segurança estabelecidas pelo Estado-membro de tratamento; e nos termos da legislação da União relativa às normas de segurança.

Ainda é importante destacar que a diretiva afirma, no seu artigo $4^{\circ}$, 4., que os Estadosmembros asseguram que os prestadores de cuidados de saúde apliquem, no seu território, aos doentes dos outros Estados-membros, a mesma tabela de preços para os cuidados de saúde que a aplicada aos doentes nacionais em situação médica comparável, ou cobrem um preço calculado de acordo com critérios objetivos e não discriminatórios, caso não haja um preço comparável para os doentes nacionais.

\footnotetext{
${ }^{8}$ UNIÃO EUROPEIA. Regulamento (CE) n. 987/2009 do Parlamento Europeu e do Conselho de 16 de Setembro de 2009 que estabelece as modalidades de aplicação do Regulamento (CE) n. 883/2004 relativo à coordenação dos sistemas de segurança social (Texto relevante para efeitos do EEE e a Suíça). Disponível em: http://eur-lex.europa.eu/legal-content/PT/TXT/PDF/?uri=CELEX:32009R0987\&from=PT. Acesso em: 23 dez. 2016.

${ }^{9}$ UNIÃO EUROPEIA. Directiva 2011/24/UE do Parlamento Europeu e do Conselho de 09 de março de 2011 relativa ao exercício do direito dos doentes em matéria de cuidados de saúde transfronteiriços. Art. $1^{\circ}, 1$. Disponível em: http://eur-lex.europa.eu/legal-content/PT/TXT/PDF/?uri=CELEX:32011L0024\&from=PT. Acesso em: 23 dez. 2016.
} 
A diretiva aborda como se dá o reembolso dos custos dos cuidados de saúde transfronteiriços, enumera alguns cuidados de saúde sujeitos à autorização prévia ${ }^{10}$ e como se dá o reconhecimento de receitas emitidas em outro Estado-membro. Trata, também, sobre o trabalho conjunto dos Estados-membros no diagnóstico de doenças raras e, por último, sobre a apresentação de um relatório de três em três anos para o Parlamento Europeu e Conselho incluindo informações sobre o funcionamento das redes europeias, fluxo de doentes, entre outras informações pertinentes que merecem acompanhamento.

O penúltimo ato legislativo pertinente sobre a temática é a Decisão n. 1082/2013/UE do Parlamento Europeu e do Conselho de 22 de outubro de 2013, relativa às ameaças sanitárias transfronteiriças graves. Traz em seu bojo que a decisão deve ser aplicada para monitorização, alerta rápido e o combate contra ameaças específicas de natureza transfronteiriça, como mercadorias, por exemplo, produtos farmacêuticos e gêneros alimentícios. Cada Estado-membro deve designar autoridades competentes para realizar a vigilância epidemiológica do seu país, autoridades responsáveis por realizar alertas e determinar medidas de proteção necessárias.

Importante destacar a existência de regulamentação própria de alguns países firmando acordos bilaterais com outros países. É o exemplo de países como: França e Portugal, que firmaram o acordo de 28 de Abril de 1999 que estabelece modalidades especiais pormenorizadas de gestão e de pagamento dos créditos recíprocos de cuidados de saúde nos termos do disposto nos Regulamentos (CEE) n. 1408/71 e (CEE) n. 574/72; Espanha e Portugal, que em 2002 firmaram acordo com o fim de estabelecer disposições pormenorizadas para a gestão e apuramento dos créditos recíprocos relativos aos cuidados de saúde com vista a facilitar e acelerar o apuramento desses créditos; Espanha e Itália, que em 1997 já possuíam a preocupação com a existência de um procedimento para melhorar e simplificar os reembolsos das despesas com cuidados de saúde, nos termos do n. 3 do artigo 36 do Regulamento (CEE) n. 1408/71 (reembolso das prestações em espécie de doença e maternidade) e dos artigos 93., 94., 95., 100. e n. 5 do artigo 102 do Regulamento (CEE) n. 574/72 (modalidades de reembolso das prestações do seguro de doença e maternidade e créditos atrasados); e cita-se também Espanha e França, que em 2005 firmaram acordo com o fim de estabelecer as modalidades específicas de

\footnotetext{
10 São exemplos trazidos pelo artigo $8^{\circ}$, aqueles que impliquem a internação hospitalar, durante pelo menos uma noite, ou que exijam equipamentos médicos altamente especializados e onerosos, que venha a representar risco especial para o doente ou para a população, ou que os serviços de saúde sejam prestados por um prestador de cuidados de saúde que possa suscitar preocupações.
} 
gestão e de apuramento dos créditos recíprocos relativos a cuidados de saúde nos termos do disposto nos Regulamentos (CEE) n. 1408/71 e (CEE) n. 574/72.

Nesse sentido, conforme $\mathrm{Abad}^{11}$ :

A política de saúde europeia pretende complementar as políticas de saúde nacionais e melhorar a saúde dos cidadãos, fomentando a cooperação e permitindo que as autoridades nacionais se beneficiem de soluções eficientes de outros Estados-Membros, para reduzir as desigualdades relacionadas à saúde ${ }^{12}$.

Ou seja, os regulamentos e diretivas que existem possuem o intuito de fomentar a cooperação entre os Estados-membros para que possa ocorrer a redução das desigualdades sanitárias no bloco da União Europeia, e ao mesmo tempo realizando a fiscalização do tratamento dispendido a pacientes que não são nacionais, através, por exemplo, do documento emitido pela instituição competente.

Vê-se que as repercussões da legislação comunitária afetaram os Estados-membros independentemente do modelo de política de saúde adotado. Foram vários os impactos, tendo em vista as condições particulares de organização e financiamento de cada sistema de saúde, em âmbito nacional ${ }^{13}$. Conclui-se que a integração europeia repercutiu nas políticas de saúde, não tanto por legislação específica implantada, mas sim com a implementação do mercado único europeu, com os aspectos econômicos de livre circulação. Quanto à regulação, financiamento, oferta, acesso e distribuição de serviços, esses temas foram abordados por cada Estado-membro.

\subsection{A Jurisprudência do Tribunal de Justiça Europeu}

O Tribunal de Justiça reconheceu que o objetivo da manutenção de um serviço médico e hospitalar equilibrado e acessível a todos pode igualmente ser abrangido por uma das derrogações, com base em razões de saúde pública, previstas no artigo 52 do TFUE, na medida em que contribua para a realização de um nível elevado de proteção da saúde. 0 Tribunal de Justiça sustentou também que os Estados-membros restrinjam a livre prestação de serviços

\footnotetext{
11 ABAD, Maria Jose Aguado. Asistencia sanitaria transfronteriza. 2015. Disponível em: www.aeds.org/congreso/XXIcongreso/docs/mariajoseaguado.docx. Acesso em: 02 jan. 2017.

${ }^{12}$ La política sanitaria europea pretende complementar las políticas sanitarias nacionales y mejorar la salud de los ciudadanos, fomentando la cooperación y, permitiendo que las autoridades nacionales se beneficien de soluciones eficientes de otros EM, para reducir las desigualdades sanitarias.

${ }_{13}$ GIOVANELLA, Ligia; GUIMARAES, Luisa. Integração européia e políticas de saúde: repercussões do mercado interno europeu no acesso aos serviços de saúde. Revista Cad. Saúde Pública, Rio de Janeiro, v. 22, n. 9, p. 1795-1807, set. 2006.
} 
médicos e hospitalares, na medida em que a manutenção da capacidade de tratamento ou de uma especialidade médica no território nacional seja essencial para a saúde pública.

Sobre os problemas encarados pelo Tribunal de Justiça referentes à temática, fala Basurko $^{14}$ :

O problema principal apontado ao Tribunal de Justiça Europeu para resolver não tem sido outro que não o de determinar os critérios ou requisitos a serem impostos para que membros de um sistema de seguridade social possam ser compensados pelas despesas que ocorrem com um tratamento médico em estado distinto ao de origem ou de filiação ${ }^{15}$.

A posição do TJUE adotada até agora mostra que houve uma consolidação da livre circulação de pacientes no contexto da livre prestação de serviços públicos, uma vez que qualquer cidadão pode mover-se para outro Estado-membro para buscar cuidados hospitalares ou não hospitalares. No que diz respeito aos tratamentos hospitalares, deve-se levar em conta a cobertura que possui no próprio Estado. A autorização prévia, regulamentada na Diretiva de 2011, será necessária se a viabilidade financeira do sistema de seguridade social assim determinar. Desse modo, o Estado em que o paciente é filiado deverá conceder a autorização prévia, com caráter obrigatório, quando o Estado-membro de inscrição não oferecer cobertura em um prazo aceitável.

Os problemas começaram a surgir no momento em que cidadãos de alguns países tentaram ter acesso aos cuidados em saúde em países distintos ao seu de origem e obterem reembolso das despesas lá efetuadas, não sobre os princípios regulamentados da livre circulação de pacientes, mas se referindo a certas liberdades econômicas (livre circulação de bens e serviços). Isso veio a exigir pronunciamento do TJUE à luz de bases jurídicas que as instituições comunitárias não tinham previsto no momento em que entraram em vigor regulamentos relacionados ao tema ${ }^{16}$.

\footnotetext{
${ }^{14}$ BASURKO, Olga Fotinopoulou. El reembolso de gastos médicos y la Directiva sobre Asistencia Sanitaria Transfronteriza. Lan Harremanak. Revista de Relaciones Laborales, n. 25, 2012, p. 332. Disponível em: http://www.ehu.eus/ojs/index.php/Lan_Harremanak/article/view/6190/5838. Acesso em: 26 dez. 2016.

${ }^{15} \mathrm{El}$ problema principal al que se ha visto abocado el Tribunal de Justicia europeo a resolver no ha sido otro que el de determinar los criterios o requisitos que cabe imponer para que los afiliados a un sistema de seguridad social puedan verse compensados por los gastos que ocasiona un tratamiento médico en un Estado distinto al de origen o de afiliación.

${ }^{16}$ BASURKO, Olga Fotinopoulou. El reembolso de gastos médicos y la Directiva sobre Asistencia Sanitaria Transfronteriza. Lan Harremanak. Revista de Relaciones Laborales, n. 25, 2012. Disponível em: http://www.ehu.eus/ojs/index.php/Lan_Harremanak/article/view/6190/5838. Acesso em: 26 dez. 2016.
} 
Dois casos conhecidos são Kholl e Decker ${ }^{17}$, em que houve demandas em face de Luxemburgo (país de inscrição), porque o primeiro havia negado o reembolso do tratamento ortodôntico do filho do demandante (caso Kholl), sob o argumento de que este não seria urgente, pois ele poderia ter esperado para realizá-lo em seu próprio país, e também negou a realização de compra de óculos receitados para Decker, sob o argumento de que não havia sido realizada a solicitação de autorização prévia, exigida pelas normas comunitárias. Ao passar pelo Tribunal, este emitiu sentenças favoráveis aos demandantes. Considerou que a exigência de autorização prévia envolveu uma restrição à livre prestação de serviços (no caso Kholl) ou à livre circulação de mercadorias (no caso Decker), pois não observou a existência de um interesse público superior que justificasse as restrições. Assim sintetiza Basurco ${ }^{18}$ :

O Tribunal de Justiça não observou - em nenhum dos casos - que existia alguma razão que justificasse as restrições ao exercício das liberdades econômicas comunitárias que ocasiona o requisito da autorização, já que - e isto é o importante - os senhores Kholl e Decker apenas haviam solicitado o reembolso dos gastos médicos até a quantia que se concederia em seu próprio país [...]. Assim, para a Corte tanto a assistência hospitalar como não hospitalar (Kholl e Decker) faziam parte da livre prestação de serviços (ou de mercadorias, em Decker), de modo e de maneira que a submissão a uma autorização prévia representaria um obstáculo à liberdade econômica que apenas poderia ser restrita por razões constrangedoras, de interesse geral, quando coloca em perigo o equilíbrio do sistema de seguridade social ou a gestão e o planejamento em matéria de saúde ${ }^{19}$.

Em 2003, outro caso que abordava a livre circulação de pacientes foi o caso Y. Watts, que em 2002 foi diagnosticado com artrose nas duas ancas, necessitando, desta forma, de uma prótese total de ambas. Assim, utilizou-se do formulário E-112 para se submeter à cirurgia necessária em país estrangeiro, mas não conseguiu de imediato, havendo assim o indeferimento do pedido sob a alegação de que o caso foi classificado como "de rotina", de modo que poderia

\footnotetext{
${ }^{17}$ Decisões formuladas pelo Tribunal em 1998.

18 BASURKO, Olga Fotinopoulou. El reembolso de gastos médicos y la Directiva sobre Asistencia Sanitaria Transfronteriza. Lan Harremanak. Revista de Relaciones Laborales, n. 25, 2012. Disponível em: http://www.ehu.eus/ojs/index.php/Lan_Harremanak/article/view/6190/5838. Acesso em: 26 dez. 2016.

19 El TJ no observó -en ninguno de los dos casos- que existiera alguna razón que justificara las restricciones al ejercicio de las libertades económicas comunitárias que ocasionaba el requisito de la autorización, ya que -y esto es lo importante- los Sres. Kholl y Decker sólo habían solicitado el reembolso de los gastos médicos hasta la cuantía que se les hubiera concedido en su propio país. (...) Así, para la corte tanto la assistência hospitalaria como no hospitalaria (Kholl y Decker) constituían parte de la libre prestación de servicios (o de mercancías en Decker), de modo y manera que el sometimiento a una autorización previa suponía un obstáculo a la citada libertad económica que sólo podía restringirse por razones imperiosas de interés general como que se pusiera en peligro el equilibrio del sistema de seguridad social o cuando peligrara la gestión y previsión sanitaria.
} 
ser prestado dentro dos prazos previstos no NHS. Por conta própria, Watts realizou a cirurgia na França e pediu reembolso do custo com estadia e hospital. O pedido foi negado pela Suprema Corte do Reino Unido (país em que reside), o que ensejou a levar o caso ao TJUE e obter sentença favorável.

Nesse sentido, de acordo com Borges:

Ao longo da década de 90 diversos casos relacionados à prestação de serviços de saúde transfronteiriços foram levados ao TJUE ${ }^{20}$. Esses processos têm como situação fática comum, pacientes que realizaram tratamentos de saúde no exterior sem autorização prévia de seus sistemas de saúde, pagando o tratamento do próprio bolso, e requerendo, posteriormente, reembolso das despesas aos sistemas de saúde de seu país de residência. A grande questão jurídica envolvida refere-se à natureza econômica ou não dos serviços de saúde e, consequentemente, se a eles se aplicam as liberdades econômicas sobre serviços. Em todos esses casos, e outros que os sucederam, o Tribunal reconheceu que os serviços de saúde têm natureza econômica e, portanto, estão sujeitos à aplicação das regras do Tratado, o que torna livre a possibilidade de receber serviços em outro país, sem necessidade de autorização prévia, já que esta, se existente, funcionaria como barreira à livre circulação de serviços. Como consequência, os Estados-Membros passaram a ter que reembolsar despesas incorridas por pacientes que realizaram tratamentos no exterior sem a autorização prévia prevista no Regulamento $883 / 2004 .{ }^{21}$

Destaca-se, por explanação dos autores no que se refere a algumas decisões do Tribunal de Justiça da União Europeia, a superioridade dos princípios de livre circulação e a sobreposição dos valores econômicos aos sociais, ocasionando o alto volume de decisões favoráveis que, a médio prazo, podem trazer dificuldades financeiras a alguns Estados-membros da UE, necessariamente aos que recebem pacientes de outros Estados para tratamentos de alto custo, o que de fato está a ocorrer. Por isso, a Diretiva trouxe a possibilidade de cada Estado-membro estabelecer como se dará o reembolso, com o fulcro de estabelecer uma certa segurança jurídica em torno dessa matéria tão complexa.

\footnotetext{
${ }^{20}$ Acórdãos de 28 de Abril de 1998, Kohll. Nos anos 2000, houve em 12 de Julho de 2001, Smit0s Geraets e Peerbooms, e em 13 de Maio de 2003, Müller-Fauré e van Riet.

21 BORGES, Danielle da Costa Leite. Princípios comuns aos sistemas de saúde da UE e justiça distributiva: efeitos da aplicação das regras do mercado interno europeu aos serviços de saúde. 2012, p. 11. Disponível em: https://www.researchgate.net/profile/Danielle_Borges/publication/303718515_Principios_comuns_aos_si stemas_de_saude_da_UE_e_justica_distributiva_efeitos_da_aplicacao_das_regras_do_mercado_interno_eu ropeu_aos_servicos_de_saude/links/574efb1e08aee47cb6e536e6.pdf. Acesso em: $26 \mathrm{dez} .2016$.
} 


\section{UM BALANÇO ENTRE GANHOS E PERDAS DOS ESTADOS E DOS USUÁRIOS}

Pretende-se abordar nos tópicos seguintes o que seria a livre circulação de pacientes e a diferenciação de prática realizada atualmente no âmbito dos Estados-membros, como o turismo sanitário e médico. Na sequência, tendo em foco a Diretiva 2011/24/EU, explica-se como se dá o reembolso dos gastos públicos e por que tal prática necessita ser muito bem normatizada para que não incorra em excessos e haja a possibilidade de existência de sistemas de saúde, no âmbito da União Europeia, digno para todos.

\section{1. "Livre" circulação de pacientes?}

Alguns Estados começaram a ser conscientes de que aumentar o número de pacientes que buscam assistência médica em outros países complicaria ainda mais tanto os custos que suportam os sistemas nacionais como o planejamento e a gestão eficaz de hospitais e centros de saúde. A questão é, por exemplo, de inegável interesse para a Espanha ${ }^{22}$, visto que é, segundo $\mathrm{Hortal}^{23}$, um dos principais destinos do denominado turismo sanitário, tanto pelo número de pessoas que procuram por um tratamento específico, quanto pelo número de europeus que elegem o lugar como o de sua residência após a aposentadoria. Além disso, argumenta Perez et.al. ${ }^{24}$ que o alto número de turismo sanitário na Espanha decorre de seu sistema de saúde ser um dos melhores do mundo, de acordo com a OMS, e também por existirem fraudes em

\footnotetext{
${ }^{22}$ Recentemente surge a preocupação com a cobertura sanitária da numerosa quantidade de residentes estrangeiros no país que o cidadão receberá os cuidados médicos. Um exemplo, trazido pelo Jornal $A B C$ Comunidad Valenciana, de 29.09.2016, é o seguinte: “O governo espanhol tratará de firmar um acordo com o Reino Unido para que pague a cobertura de saúde da númerosa quantidade de residentes britânicos no país". (El Gobierno español tratará de cerrar un acuerdo con el Reino Unido para que pague la cobertura sanitaria de la numerosa colonia de residentes británicos en el país). Ou seja, buscam-se acordos para que pessoas que residam em um país possam ter acesso aos serviços de saúde geridos pelo seu país de origem.

ABC Comunidad Valenciana. El Gobierno negociará con el Reino Unido que pague los gastos médicos de sus residentes en España. 2016. Disponível em: http://www.abc.es/espana/comunidad-valenciana/abcigobierno-negociara-reino-unido-pague-gastos-medicos-residentes-espana-201609291639_noticia.html. Acesso em: 26 set. 2016.

${ }^{23}$ HORTAL, María José Cervell. Pacientes en la Unión Europea: libertad restringida y vigilada. Cuadernos de derecho transnacional, v. 3, n. 2, p. 51-70, 2011. Disponível em: https: / /dialnet.unirioja.es/servlet/articulo?codigo=3733935. Acesso em: 26 dez. 2016.

${ }^{24}$ PÉREZ, Cristina Díaz; REBOLLO, Elena Chamorro. Influencia del turismo sanitario em la sostenibilidad financeira del sistema público de salud. Revistas Derecho y salud. v. 24, extra, 2014. Disponível em: http://www.ajs.es/revista-derecho-y-salud/influencia-del-turismo-sanitario-en-la-sostenibilidadfinanciera-del-sistema-publico-de-salud. Acesso em: 27 dez. 2016.
} 
decorrência do uso do cartão de saúde por não residentes, o que inevitavelmente ocasiona altos gastos com saúde no país e tem se tornado uma preocupação para o Estado-membro.

Há, então, dois tipos de atendimento de saúde, em função do tempo: os programados para aqueles de outra localidade que "agendam" atendimento em virtude da necessidade de urgência e da impossibilidade de espera no seu país de origem - e os não programados, para aqueles que estão temporariamente em um território.

A legislação da União Europeia diz que o cidadão europeu, se adoecer durante uma estadia temporária noutro país da UE, quer se trate de férias, de uma viagem de negócios ou de um período de estudos no estrangeiro, tem direito a receber os cuidados médicos necessários nas mesmas condições que as pessoas cobertas pelo sistema de saúde desse país, basta para isso que leve consigo o cartão europeu de seguro de doença ${ }^{25}$, que prova que está coberto pelo sistema de segurança social de um país da UE.

Nesse sentido, explica Basurko ${ }^{26}$ :

Tanto em um como no outro caso, os pacientes teriam direito a obter assistência médica em outro Estado nas mesmas condições que tiveram os assegurados do país, sempre e quando, no primeiro caso, o paciente possua o documento derivado do formulário E-11 (substituído na atualidade pelo cartão de saúde europeu) ou, em segundo caso, que o tratamento tenha sido previamente autorizado pelo Estado de filiação do cidadão em questão ${ }^{27}$.

Caso não possua cartão no estrangeiro ou não possa utilizá-lo (como quando o paciente recorre ao setor privado), o país que ele está temporariamente não pode recusar tratamento, mas é possível que o paciente tenha que custeá-lo e, depois, quando regressar ao país que reside, solicitar o reembolso. Os procedimentos são muito diferentes consoante se trate de cuidados de saúde não programados (caso adoeça subitamente durante uma estadia no estrangeiro) ou de cuidados de saúde programados (caso se desloque a outro país da UE expressamente para receber um tratamento médico específico).

\footnotetext{
${ }^{25} \mathrm{O}$ cartão é gratuito. Solicita-se gratuitamente o cartão junto do organismo responsável pela cobertura médica antes de partir em viagem.

${ }^{26}$ BASURKO, Olga Fotinopoulou. El reembolso de gastos médicos y la Directiva sobre Asistencia Sanitaria Transfronteriza. Lan Harremanak. Revista de Relaciones Laborales, n. 25, 2012. Disponível em: http://www.ehu.eus/ojs/index.php/Lan_Harremanak/article/view/6190/5838. Acesso em: 26 dez. 2016.

${ }^{27}$ Tanto en uno como en otro caso, los pacientes tenían derecho a obtener la asistencia médica en ese otro Estado en las mismas condiciones que tuvieran los asegurados en aquél, siempre y cuando, en el primer caso, el paciente contara con el documento derivado de la presentación del formulario E-111 (sustituido en la actualidad por la tarjeta sanitaria europea) o, en el segundo caso, siempre que el tratamiento hubiera sido previamente autorizado por el Estado de afiliación del ciudadano en cuestión.
} 
OS SISTEMAS DE SAÚDE NO ÂMBITO DA UNIÃO EUROPEIA E A PRÁTICA DE TURISMO SANITÁRIO: BREVE ANÁLISE SOBRE AS REPERCUSSÕES TRAZIDAS PARA O BLOCO

MANUEL FONDEVILA MARÓN FERNANDA DAYANE DOS SANTOS QUEIROZ

Ponto importante a ser observado, conforme enumera Borges $^{28}$, refere-se ao fato de 0 paciente se submeter a tratamentos fora do seu país e sem autorização prévia - nesse caso, ele deverá custear a viagem e o tratamento com recursos próprios e solicitar o reembolso quando retornar ao seu país de origem. Essa abertura dada pelas decisões do Tribunal de Justiça da União Europeia e, posteriormente, normatizada pela Diretiva de 2011, permite que pessoas com maior poder aquisitivo busquem o tratamento imediato em país que o forneça com qualidade (visto que terão reembolso) e tal prática pode interferir de forma negativa na equidade de tratamento entre os pacientes, podendo ainda aflorar a realização do turismo médico ${ }^{29}$.

Esse conceito não se confunde com o de cuidados de saúde transfronteiriços, que permite a livre circulação de pacientes, tratado ao longo do artigo, utilizado no âmbito da concessão de serviços públicos de saúde de um país a outro da União Europeia, após a constatação de necessidade de urgência, assinatura de autorização prévia do país de origem para realizar o tratamento em outro país do bloco, e após ser reembolsado, inclusive com hospedagem, se o Estado-membro regulamentar, de acordo com a Diretiva 2011/24/UE, item $(34)^{30}$.

${ }^{28}$ BORGES, Danielle da Costa Leite. Princípios comuns aos sistemas de saúde da UE e justiça distributiva: efeitos da aplicação das regras do mercado interno europeu aos serviços de saúde. Disponível em:

https://www.researchgate.net/profile/Danielle_Borges/publication/303718515_Principios_comuns_aos_si stemas_de_saude_da_UE_e_justica_distributiva_efeitos_da_aplicacao_das_regras_do_mercado_interno_eu ropeu_aos_servicos_de_saude/links/574efb1e08aee47cb6e536e6.pdf. Acesso em: 26 dez. 2016.

29 Devido às motivações, cada vez mais diversas, que levam os turistas a viajar por motivos de saúde, surgiu o conceito de Turismo Médico, o qual se define como o ato de viajar do local de residência para outro local dentro do país (Turismo Médico Doméstico) ou para fora do país de residência (Turismo Médico Internacional) com o objetivo primário de receber cuidados médicos e, simultaneamente, usufruir da parte turística do destino. In: DELOITTE. Medical Tourism - Consumers in Search of Value, 2008. Disponível

em: http://www.deloitte.com/assets/DcomunitedStates/Local\%20Assets/Documents/us_chs_MedicalTourismSt udy(3).pdf. Acesso em: 16 jan. 2017.

${ }^{30}$ (34) Os Estados-Membros de afiliação deverão conceder aos doentes o direito de receber noutro Estado-

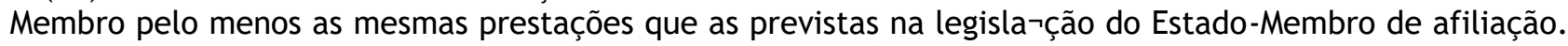
Se a lista das prestações não indicar especificamente o método de tratamento aplicado mas definir tipos

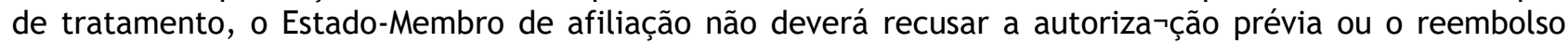
baseando-se no facto de o método de tratamento não estar disponível no seu território, mas sim verificar se o tratamento fronteiriço pretendido ou recebido corresponde às prestações previstas na sua legislação. 0 facto de a obrigação de reembolsar cuidados de saúde transfronteiriços nos termos da presente directiva ser limitada aos cuidados que figuram entre as prestações a que o doente tem direito no seu Estado-Membro de afiliação não deverá impedir os Estados-Membros de reembolsar os custos de cuidados de saúde transfronteiriços que ultrapassem esses limites. Os Estados-Membros podem, por exemplo, reembolsar custos adicionais, tais como despesas de alojamento, de viagem ou despesas suplementares suportadas por pessoas com deficiência, mesmo que esses custos não sejam reembolsados no caso de cuidados de saúde prestados no seu território. 
OS SISTEMAS DE SAÚDE NO ÂMBITO DA UNIÃO EUROPEIA E A PRÁTICA DE TURISMO SANITÁRIO: BREVE ANÁLISE SOBRE AS REPERCUSSÕES TRAZIDAS PARA O BLOCO

MANUEL FONDEVILA MARÓN FERNANDA DAYANE DOS SANTOS QUEIROZ

\section{Chapaprieta e Peréz ${ }^{31}$ também tratam da diferença entre turismo de saúde, a} assistência médica a estrangeiros fornecida pelo setor privado, e o termo turismo sanitário, que seria a assistência médica fornecida pelo sistema público de saúde. Continuam afirmando sobre a assistência médica ministrada no setor público que: "A partir desta perspectiva, o conceito de turista é mais restrito, pois a motivação principal da viagem é receber um tratamento médico, portanto se exclui o turismo de saúde e bem-estar e este se associa com o ócio e desfrute

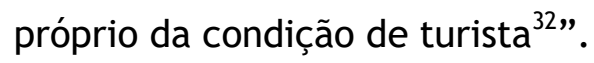

Flores $^{33}$ diferencia os termos da seguinte forma:

Dentro do conceito de "turismo sanitário" englobam-se, pelo menos, dois fenômenos diferenciados. O que poderia ser denominado como "turismo privado" e o que cabe ser qualificado como "turismo sanitário em um contexto público". Este último, por sua vez, admite uma dupla modalidade, de acordo com ser ou não ser residente no país em que recebe assistência de saúde ${ }^{34}$.

Vê-se que o perigo é que após a regulamentação dos cuidados em saúde transfronteiriços continue a existir turismo sanitário público, ou seja, que os pacientes, tendo em vista a possibilidade de reembolso com recursos do seu Estado, busquem receber os melhores cuidados médicos. Ter a prática de turismo sanitário público ${ }^{35}$ no âmbito da União Europeia é resultado da existência de sistemas de saúde ineficientes.

31 CHAPAPRIETA, Alejandra Giraldo; PÉREZ, Ester Méndez. El turismo sanitario en España: mitos y realidades. Comunitania: Revista internacional de trabajo social y ciencias sociales, n. 9, p. 93, 2015. Disponível em: https: //dialnet.unirioja.es/servlet/articulo?codigo=5129691. Acesso em: 27 dez. 2016.

32 Desde esta óptica el concepto de turista es más restrictivo pues la motivación principal del viaje es recibir un tratamiento médico, por lo tanto se excluye el turismo de salud y bienestar que se asocia con el ocio y disfrute propios de la condición de turista.

${ }^{33}$ FLORES, Luiz Fernando Barrios. Europa y sanidade pública: el fenómeno del turismo sanitario. XIV Congreso Derecho y Salud, v. 14, mar. 2006, p. 77. Disponível em: https://dialnet.unirioja.es/descarga/articulo/5155121.pdf. Acesso em: 17 jan. 2017.

${ }^{34}$ Dentro del concepto de "turismo sanitario" se engloban, al menos, dos fenómenos diferenciados. El que podría denominarse "turismo privado" y el que cabe calificar de "turismo sanitario en un contexto público". Este último, a su vez, admitiría una doble modalidad, según fuera ejercido por residentes o no residentes en el país en el que se recibe la asistencia.

35 O turismo sanitário na Espanha, por exemplo, é uma realidade. Vejamos o exemplo: Desde que en Gran Bretaña las listas de espera se alargan hasta los tres años, son los ingleses los que más se están aficionando a convertir las vacaciones quirúrgicas en un turismo de masas, seguidos de alemanes o belgas. Hay páginas donde se les llegan a comparar cuánto dinero se ahorrarían si se operan en España. Todos sacan provecho de la reglamentación europea que permite a los ciudadanos miembros del bloque recibir tratamiento médico en cualquier país de la UE. Por eso los gestores del turismo español incluyen ya en las páginas web de municipios playeros, junto a la lista de bellezas locales, hospitales y centros de salud. Hasta el momento el éxito es total, aunque nadie se atreve a dar cifras concretas de la población europea que se afinca en España para disfrutar de estas maravillas. In: EL CONFIDENCIAL. Se acabó el 'turismo sanitario' para 700.000 extranjeros y con 1.000 millones de coste. 2012. Disponível em: 
Hortal $^{36}$ considera que a Diretiva limita a perspectiva trazida pelo Tribunal de Justiça da União Europeia no que se refere à livre circulação de pacientes e ainda assim considera que o paciente do bloco sai ganhando, pois a Diretiva potencializou muito o conhecimento público acerca das possibilidades de buscar assistência de saúde fora, de modo que, para muitos cidadãos, o sacrifício possa vir a compensar. Com a Diretiva, se expandiram as possibilidades de recusa de autorização prévia, pois há critérios para fazê-la, que podem chegar a gerar decisões arbitrárias, mas é um preço a se pagar. Mas, para evitar grandes divergências, adota-se o princípio da subsidiariedade e os Estados-membros continuam sendo os responsáveis pela organização dos seus sistemas.

\subsection{O reembolso dos gastos e a prestação de serviços de saúde aos usuários}

Como já foi mencionado em tópico anterior, em 2011 foi adotada a Diretiva 2011/24/UE do Parlamento e do Conselho com o intuito de regular distintos problemas que surgem quando os serviços de saúde são ministrados em local diferente em que mora o paciente. Como já menciona a própria diretiva, nas considerações iniciais, algumas questões referentes ao reembolso dos custos relativos a cuidados de saúde prestados na UE em Estado-membro distinto do que vive o paciente já foram tratados em alguns julgados do Tribunal de Justiça Europeu, de forma avulsa, o que ocasionou a necessidade de tratar o assunto na referida Diretiva.

No artigo $1^{\circ}$ da Diretiva já se demonstra quem tem direito ao reembolso: pessoa segurada que receba cuidados de saúde transfronteiriços, e ainda se os cuidados de saúde em questão figurarem entre as prestações a que a pessoa segurada tem direito no Estado-membro de afiliação. Ou seja, tem direito ao reembolso quando, na sua localidade também, a pessoa segurada tem direito àquele cuidado de saúde. A normativa coloca que é reembolsado, em regra, até o limite do custo que o paciente teria no país de origem, mas a norma abre uma exceção no caso da totalidade dos custos com cuidados de saúde transfronteiriços exceder o nível dos custos no local. Nesse caso, cabe ao Estado-membro, tendo em vista suas finanças, poder decidir reembolsar na integralidade.

http://www.elconfidencial.com/espana/2012-04-19/se-acabo-el-turismo-sanitario-para-700-000extranjeros-y-con-1-000-millones-de-coste_232957/. Acesso em: 17 jan. 2017.

${ }^{36}$ HORTAL, María José Cervell. Pacientes en la Unión Europea: libertad restringida y vigilada. Cuadernos de derecho transnacional, v. 3, n. 2, p. 51-70, 2011. Disponível em: https: / /dialnet.unirioja.es/servlet/articulo?codigo=3733935. Acesso em: 26 dez. 2016. 
É também abordado pela Diretiva mencionada que cabe ao Estado-membro de afiliação determinar, a nível local, regional ou nacional, os cuidados de saúde a cuja assunção de custos a pessoa segurada tem direito e o limite de assunção desses custos, independentemente do local de prestação dos cuidados de saúde em causa ${ }^{37}$. Além do reembolso dos custos com cuidado de saúde, a normativa traz que também podem ser reembolsados, a critério do Estado-membro de afiliação, valores gastos com alojamento, viagem ou custos suplementares, nos quais as pessoas com deficiência podem incorrer quando recebem cuidados de saúde transfronteiriços devido a uma ou mais deficiências, mas deve ocorrer de acordo com a legislação nacional e desde que exista documentação suficiente comprovativa desses custos.

Essa garantia do reembolso gera uma preocupação a menos àqueles enfermos que buscam tratamento em outra localidade, mas ao mesmo tempo pode propiciar um "mercado interno" em que países referência em cuidado de uma determinada enfermidade aumentem os valores dos tratamentos, além de pacientes que incorporem diversos custos obtidos no seu translado, pois sabem que na maioria das vezes podem ter o reembolso integral, tal como traz a Diretiva analisada.

\section{A IMPORTÂNCIA DA COOPERAÇÃO EM MATÉRIA DE SAÚDE NO BLOCO DA UNIÃO EUROPEIA}

Traz a Diretiva 2011/24/EU, ainda em suas considerações iniciais, que para garantir cuidados de saúde transfronteiriços seguros, eficientes e de elevada qualidade, os Estadosmembros devem facilitar a cooperação entre os prestadores de cuidados de saúde, os utentes e os reguladores dos diferentes Estados-membros, a nível nacional, regional ou local. Isso pois, a prestação de serviços transfronteiriços pode constituir a forma mais eficiente de organizar os serviços de saúde para as populações locais, e também a prestação continuada desses serviços exige uma cooperação entre os sistemas de saúde dos diferentes Estados-membros. Essa cooperação, conforme trata a legislação, pode incluir o planejamento conjunto, o reconhecimento mútuo ou a adaptação de procedimentos ou normas, a interoperabilidade dos respectivos sistemas nacionais de tecnologias de informação e comunicação, mecanismos práticos que assegurem a continuidade dos cuidados de saúde ou medidas que facilitem na

\footnotetext{
${ }^{37}$ Diretiva 2011/24/EU, art. $2^{\circ}, 3$.
} 
prática a prestação, por profissionais de saúde, de cuidados de saúde transfronteiriços numa base temporária ou ocasional.

0 art. 10 da Diretiva traz a necessidade de existir cooperação no domínio dos cuidados de saúde sobre normas e orientações em matéria de qualidade e segurança e o intercâmbio de informações. Na sequência, afirma-se que a cooperação ocorre quando os Estados-membros a observam no domínio da prestação de cuidados de saúde transfronteiriços aos níveis regional e local, bem como através das tecnologias da informação e da comunicação.

Há ainda referência à participação de uma Comissão para promover o incentivo à cooperação entre os Estados-membros, principalmente os Estados limítrofes, a celebrarem acordos entre si. A Comissão incentiva igualmente os Estados-membros a cooperarem na prestação de cuidados de saúde transfronteiriços nas regiões fronteiriças. Mas, por conta das divergências entre os sistemas de saúde e do "aproveitamento" de alguns países sobre essa vantagem que possuem, leva-se à necessidade de uma revisão de projetos de cooperação e assistência em saúde entre regiões ou Estados-membros, vários destes localizados nas fronteiras, com o fim de melhorar possibilidades de acesso e ampliar serviços ofertados. Na opinião de Nebreda $^{38}$, “provavelmente, o que está faltando na política de saúde europeia é uma maior cooperação interestatal. O Mercado Único é uma realidade e alguns de seus princípios e realizações deveriam ser aplicados no âmbito da saúde" ${ }^{39}$.

As principais ações de cooperação, vistas como mais necessárias no âmbito da União Europeia, na percepção de Borges $^{40}$, são em emergências (ambulâncias, equipes de resgate, equipamentos), assistência (serviços complementares), telemedicina (consulta, diagnóstico, compartilhamento de dados e troca de experiência), compra e utilização de equipamentos, pesquisa, recursos humanos, rede de boas práticas e estabelecimento de estruturas comuns.

\footnotetext{
${ }^{38}$ NEBREDA, Carlos García de Cortárzar y. ¿Libre circulación de pacientes en la Unión Europea? La atención de los dependientes y la tarjeta sanitaria europea. Revista del Ministerio de trabajo y asuntos sociales, n. $47,48.4$ p. 48 em: http://www.empleo.gob.es/es/publica/pub_electronicas/destacadas/revista/numeros/47/est02.pdf. Acesso em: 17 jan. 2017.

39 Probablemente lo que esté faltando en la política sanitaria europea es una mayor cooperación interestatal. El Mercado Único es una realidad y algunos de sus principios y logros deberían ser aplicados en el ámbito de la salud.

40 BORGES, Danielle da Costa Leite. Princípios comuns aos sistemas de saúde da UE e justiça distributiva: efeitos da aplicação das regras do mercado interno europeu aos serviços de saúde. Disponível em:

https://www.researchgate.net/profile/Danielle_Borges/publication/303718515_Principios_comuns_aos_si stemas_de_saude_da_UE_e_justica_distributiva_efeitos_da_aplicacao_das_regras_do_mercado_interno_eu ropeu_aos_servicos_de_saude/links/574efb1e08aee47cb6e536e6.pdf. Acesso em: $26 \mathrm{dez} .2016$.
} 
Ressalta-se que para os pacientes os fatores mais importantes para a existência da cooperação entre Estados-membros é a otimização do tempo de espera, nível de cuidado e distância. Para os profissionais de saúde, contatos com o sistema do outro país e a falta de recursos locais são os fatores mais mencionados para a ocorrência do encaminhamento do paciente a outro país e, com isso, praticar a cooperação.

A cooperação deve existir ainda em prol de descobertas, estudos, diagnósticos, em que os Estados-membros devem buscar soluções conjuntas para tratamentos de saúde e assim buscar a ocorrência de menos casos de prática de turismo sanitário. Para exemplificar, Gomez ${ }^{41}$ relata que a cooperação entre Espanha com os outros Estados da UE consiste em informações sobre profissionais de saúde, reconhecimento de receitas expedidas em outro Estado-membro, informações sobre as enfermidades raras e evolução das tecnologias de saúde.

\section{CONCLUSÃO}

O presente artigo buscou analisar a legislação e o aparato jurisprudencial do bloco, com enfoque na ocorrência da circulação de pacientes para cuidados de saúde transfronteiriços e, por outro lado, observar se estes favorecem a prática do turismo sanitário no âmbito da União Europeia.

Por meio do Regulamento (CE) 883/2004, relativo à coordenação dos sistemas de segurança social, e do Regulamento (CE) 987/2009, que estabelece as modalidades de aplicação do primeiro regulamento aqui citado (Reg. 883/2004), e ainda da Diretiva 2011/24/UE, relativa ao exercício dos direitos dos doentes em matéria de cuidados de saúde transfronteiriços, bem como dos autores aqui abordados, como Chapaprieta, Peréz e Deloitte, foi possível compreender em que consiste a prática do turismo sanitário e sua diferenciação da simples livre circulação de pacientes no âmbito da União Europeia. É inegável a importância da organização do bloco da União Europeia de modo a possibilitar a existência de um cartão de saúde, possibilidade de livre circulação de pacientes, obedecendo ao disposto nos regulamentos e na diretiva, para a realização da garantia do direito à saúde em todo o bloco econômico da União Europeia.

41 GOMEZ, Gustavo Merino. La asistencia sanitaria transfronteriza: contenidos y límites. Cadernos IberAmericanos Direito Sanitário, Brasília, v.2, n.2, jul./dez. 2013, p. 920-931. Anais dos III Congresso Iberoamericano de Direito Sanitário / II Congresso Brasileiro de Direito Sanitário. Disponível em: http://publicaciones.fmdv.org/ojs/index.php/cuadernosderechosanitario/article/view/92. Acesso em: 21 jan. 2017. 
OS SISTEMAS DE SAÚDE NO ÂMBITO DA UNIÃO EUROPEIA E A PRÁTICA DE TURISMO SANITÁRIO: BREVE ANÁLISE SOBRE AS REPERCUSSÕES TRAZIDAS PARA O BLOCO

É importante destacar que, antes mesmo das diretivas, já existiam muitos julgados do Tribunal de Justiça Europeu favoráveis ao reembolso em toda e qualquer situação e o deferimento da realização da quase totalidade dos pedidos de tratamento, de cunho oneroso, em ambiente hospitalar, inclusive sem a necessidade de autorização prévia. Na perspectiva territorial, a jurisprudência fortalece o esforço comunitário de romper fronteiras, garantir a aplicação do direito em outro Estado-membro e resguardar a soberania da responsabilidade pelos cuidados de saúde em cada país ${ }^{42}$.

Essas modificações, as quais ensejaram a implantação da Diretiva de 2011, partiram então do Judiciário ${ }^{43}$ e foram vistas como algo problemático para o planejamento e gestão dos sistemas de saúde dos Estados-membros. Hoje, a Diretiva ainda traz uma série de permissões, que beneficia em especial aqueles que possuem maior poder aquisitivo e que podem, por exemplo, pagar tratamentos de saúde em outra localidade, custear hospedagem, passagens, custos adicionais, na expectativa de que serão reembolsados, muitas vezes, na integralidade dos seus gastos, bastando que demonstrem que os obtiveram. ${ }^{44}$ Nesse sentido, uma sociedade justa na ótica liberal não é aquela que busca promover o bem geral ou uma distribuição igualitária, mas sim aquela que promove os direitos e as liberdades individuais e que protege seus indivíduos de qualquer tipo de intervenção do Estado que possa afetar as liberdades e escolhas dos cidadãos ${ }^{45}$.

\footnotetext{
42 QUEIROZ, Luisa Guimarães. Integração Econômica Regional e Políticas de Saúde: União Européia e Mercosul. Rio de Janeiro: ENSP/FIOCRUZ/MS, 2007. 365 p. Tese (Doutorado). Programa de Pós-Graduação em Saúde Pública, Escola Nacional de Saúde Pública Sergio Arouca, 2007. Disponível em: http://www.arca.fiocruz.br/bitstream/icict/4496/2/289.pdf. Acesso em: 26 dez. 2016.

${ }^{43} \mathrm{Na}$ opinião de Nebreda: No es que el Tribunal de Justicia haya abogado por el turismo sanitario, pero es verdad que ha dado alas a algunos colectivos para un ejercicio abusivo de esta práctica. In: NEBREDA, Carlos García de Cortárzar y. ¿Libre circulación de pacientes en la Unión Europea? La atención de los dependientes y la tarjeta sanitaria europea. Revista del Ministerio de trabajo y asuntos sociales, n. 47. Disponível

http://www.empleo.gob.es/es/publica/pub_electronicas/destacadas/revista/numeros/47/est02.pdf. Acesso em: 17 jan. 2017.

${ }^{44}$ UNIÃO EUROPEIA. Directiva 2011/24/UE do Parlamento Europeu e do Conselho de 09 de março de 2011 relativa ao exercício do direito dos doentes em matéria de cuidados de saúde transfronteiriços. Disponível em: http://eur-lex.europa.eu/legal-content/PT/TXT/PDF/?uri=CELEX:32011L0024\&from=PT. Acesso em: 23 dez. 2016.

45 BORGES, Danielle da Costa Leite. Princípios comuns aos sistemas de saúde da UE e justiça distributiva: efeitos da aplicação das regras do mercado interno europeu aos serviços de saúde. Disponível em:

https://www.researchgate.net/profile/Danielle_Borges/publication/303718515_Principios_comuns_aos_si stemas_de_saude_da_UE_e_justica_distributiva_efeitos_da_aplicacao_das_regras_do_mercado_interno_eu ropeu_aos_servicos_de_saude/links/574efb1e08aee47cb6e536e6.pdf. Acesso em: $26 \mathrm{dez} .2016$.
} 
Outra problemática visualizada e tratada rapidamente no artigo, apenas para diferenciação de termos, é a prática do chamado turismo sanitário, no setor particular de saúde, no âmbito da União Europeia. Esse consiste na “captação” de pacientes para o seu Estadomembro, por possuir boa destinação orçamentária para a saúde, maior desenvolvimento, bons hospitais, investindo-se também na recepção de pacientes e familiares como turistas, fazendo de tal prática lucrativa.

É possível dizer que as regras do Mercado Interno europeu introduziram novos valores no campo dos serviços de saúde, valores estes que se aproximam de uma visão mais liberal e individualista da prestação de serviços de saúde, a qual vai de encontro ao caráter social, originalmente conferido a estes serviços ${ }^{46}$. Inúmeros problemas podem surgir a partir dessa liberalização na busca de prestadores no exterior, tais como o incentivo para prestadores privados e a criação de um mercado para verdadeiro turismo médico num contexto de financiamento essencialmente público. Daí decorrem, ainda, problemas de como garantir a qualidade dos serviços transfronteiriços, já que pagos por determinado país, mas realizados fora dele, e de responsabilização em caso de falha na prestação.

Por isso, para não incorrer no problema da prática do turismo sanitário, deve-se pensar e buscar realizar puramente a circulação de pacientes no âmbito da União Europeia, retirandose o termo “livre" ${ }^{47}$. Veja-se: “Agora bem, circulação de pacientes sim, livre circulação de pacientes já é outra história ${ }^{48 "}$.

A circulação de pessoas no território europeu em busca de tratamentos e de serviços de saúde, em virtude de grandes filas no país de origem, por exemplo, é considerado um direito, uma garantia dos cuidados de saúde aos cidadãos do bloco, ainda que para o alcance do acesso aos serviços de saúde essas pessoas precisem se submeter a algumas condições, como à autorização prévia. Desta forma, é visto como necessário proceder com a regulamentação e o não afrouxamento do que foi regulamentado para que qualquer paciente que necessite dos

46 BORGES, Danielle da Costa Leite. Princípios comuns aos sistemas de saúde da UE e justiça distributiva: efeitos da aplicação das regras do mercado interno europeu aos serviços de saúde. Disponível em:

https://www.researchgate.net/profile/Danielle_Borges/publication/303718515_Principios_comuns_aos_si stemas_de_saude_da_UE_e_justica_distributiva_efeitos_da_aplicacao_das_regras_do_mercado_interno_eu ropeu_aos_servicos_de_saude/links/574efb1e08aee47cb6e536e6.pdf. Acesso em: $26 \mathrm{dez} .2016$.

${ }^{47}$ NEBREDA, Carlos García de Cortárzar y. ¿Libre circulación de pacientes en la Unión Europea? La atención de los dependientes y la tarjeta sanitaria europea. Revista del Ministerio de trabajo y asuntos sociales, $\mathrm{n} . \quad 47 . \quad$ Disponível em: http://www.empleo.gob.es/es/publica/pub_electronicas/destacadas/revista/numeros/47/est02.pdf. Acesso em: 17 jan. 2017.

${ }^{48}$ Ahora bien, circulación de pacientes sí, libre circulación de pacientes ya es otro cantar. 
cuidados em saúde e que cumpra as disposições previstas possa se deslocar do seu país para receber tratamento em outro Estado-membro.

Percebe-se o quão importante é a cooperação entre os Estados-membros para buscar assistência mútua, soluções de tratamentos, estudos e pesquisas em prol da saúde do bloco da União Europeia como um todo e, paralelo a isso, diante da configuração dos países em bloco, que haja a ocorrência de circulação de pacientes para cuidados de saúde, respeitando o disposto nos regulamentos e diretivas, de forma a garantir o direito à saúde.

Ocorre que a prática do turismo sanitário é presente, de modo que existe até mesmo fraude para utilização do cartão de saúde por não residentes no bloco, ocasionando alto gasto sanitário. Como propostas de soluções a essa prática, tem-se a realização de melhorias das técnicas de faturamento para que o custo da assistência sanitária possa ser repassado aos respectivos países de origem, compensação econômica eficiente para a atenção aos pacientes da região, estabelecendo um sistema eficaz de faturamento e, por fim, realização de monitorização e até mesmo punição para casos de existência de uso fraudulento do cartão de saúde.

\section{REFERÊNCIAS}

ABAD, Maria Jose Aguado. Asistencia sanitaria transfronteriza. 2015. Disponível em: www.aeds.org/congreso/XXIcongreso/docs/mariajoseaguado.docx. Acesso em: 02 jan. 2017.

$A B C$ Comunidad Valenciana. El Gobierno negociará con el Reino Unido que pague los gastos médicos de sus residentes en España. 2016. Disponível em:

http://www.abc.es/espana/comunidad-valenciana/abci-gobierno-negociara-reino-unido-paguegastos-medicos-residentes-espana-201609291639_noticia.html. Acesso em: 26 set. 2016.

BASURKO, Olga Fotinopoulou. El reembolso de gastos médicos y la Directiva sobre Asistencia Sanitaria Transfronteriza. Lan Harremanak. Revista de Relaciones Laborales, n. 25, 2012. Disponível em: http://www.ehu.eus/ojs/index.php/Lan_Harremanak/article/view/6190/5838. Acesso em: 26 dez. 2016.

BORGES, Danielle da Costa Leite. Princípios comuns aos sistemas de saúde da UE e justiça distributiva: efeitos da aplicação das regras do mercado interno europeu aos serviços de saúde. Disponível em:

https://www.researchgate.net/profile/Danielle_Borges/publication/303718515_Principios_comu ns_aos_sistemas_de_saude_da_UE_e_justica_distributiva_efeitos_da_aplicacao_das_regras_do_m ercado_interno_europeu_aos_servicos_de_saude/links/574efb1e08aee47cb6e536e6.pdf. Acesso em: 26 dez. 2016. 
OS SISTEMAS DE SAÚDE NO ÂMBITO DA UNIÃO EUROPEIA E A PRÁTICA DE TURISMO SANITÁRIO: BREVE ANÁLISE SOBRE AS REPERCUSSÕES TRAZIDAS PARA O BLOCO

CARDO, Iván Antonio Rodríguez. El fomento del turismo sanitario en la Unión Europea: la decisiva labor del tribunal de justicia. Revista de Direito do Trabalho, São Paulo: Revista dos Tribunais, v. 36, n. 137, p. 309-331, jan./mar. 2010.

CENTRO Europeu Consumidor Portugal. Cuidados de saúde na União Europeia: em caso de doença ou acidente. Disponível em: http://cec.consumidor.pt/topicos1/cuidados-saude-naue.aspx. Acesso em: 20 jan. 2017.

CHAPAPRIETA, Alejandra Giraldo; PÉREZ, Ester Méndez. El turismo sanitario en España: mitos y realidades. Comunitania: Revista internacional de trabajo social y ciencias sociales, n. 9, p. 93, 2015. Disponível em: https://dialnet.unirioja.es/servlet/articulo?codigo=5129691. Acesso em: 27 dez. 2016.

DELOITTE. Medical Tourism - Consumers in Search of Value, 2008. Disponível em: http://www.deloitte.com/assets/DcomunitedStates/Local\%20Assets/Documents/us_chs_Medical TourismStudy(3).pdf. Acesso em: 16 jan. 2017.

EL CONFIDENCIAL. Se acabó el 'turismo sanitario' para 700.000 extranjeros y con 1.000 millones de coste. 2012. Disponível em: http://www.elconfidencial.com/espana/2012-0419/se-acabo-el-turismo-sanitario-para-700-000-extranjeros-y-con-1-000-millones-decoste_232957/. Acesso em: 17 jan. 2017.

FLORES, Luiz Fernando Barrios. Europa y sanidade pública: el fenómeno del turismo sanitario. XIV Congreso Derecho y Salud, v. 14, mar. 2006, p. 77. Disponível em: https://dialnet.unirioja.es/descarga/articulo/5155121.pdf. Acesso em: 17 jan. 2017.

GIOVANELLA, Ligia; GUIMARAES, Luisa. Integração européia e políticas de saúde: repercussões do mercado interno europeu no acesso aos serviços de saúde. Revista Cad. Saúde Pública, Rio de Janeiro, v. 22, n. 9, p. 1795-1807, set. 2006.

GOMEZ, Gustavo Merino. La asistencia sanitaria transfronteriza: contenidos y límites. Cadernos IberAmericanos Direito Sanitário, Brasília, v.2, n.2, jul./dez. 2013, p. 920-931. Anais dos III Congresso Iberoamericano de Direito Sanitário / II Congresso Brasileiro de Direito Sanitário. Disponível em:

http://publicaciones.fmdv.org/ojs/index.php/cuadernosderechosanitario/article/view/92. Acesso em: 21 jan. 2017.

HORTAL, María José Cervell. Pacientes en la Unión Europea: libertad restringida y vigilada. Cuadernos de derecho transnacional, v. 3, n. 2, p. 51-70, 2011. Disponível em: https://dialnet.unirioja.es/servlet/articulo?codigo=3733935. Acesso em: 26 dez. 2016.

NEBREDA, Carlos García de Cortárzar y. ¿Libre circulación de pacientes en la Unión Europea? La atención de los dependientes y la tarjeta sanitaria europea. Revista del Ministerio de trabajo y asuntos sociales, n. 47. Disponível em:

http://www.empleo.gob.es/es/publica/pub_electronicas/destacadas/revista/numeros/47/est02 .pdf. Acesso em: 17 jan. 2017.

PÉREZ, Cristina Díaz; REBOLLO, Elena Chamorro. Influencia del turismo sanitario em la sostenibilidad financeira del sistema público de salud. Revistas Derecho y salud. v. 24, extra, 
OS SISTEMAS DE SAÚDE NO ÂMBITO DA UNIÃO EUROPEIA E A PRÁTICA DE TURISMO SANITÁRIO: BREVE ANÁLISE SOBRE AS REPERCUSSÕES TRAZIDAS PARA O BLOCO

2014. Disponível em: http://www.ajs.es/revista-derecho-y-salud/influencia-del-turismosanitario-en-la-sostenibilidad-financiera-del-sistema-publico-de-salud. Acesso em: 27 dez. 2016.

QUEIROZ, Luisa Guimarães. Integração Econômica Regional e Políticas de Saúde: União Européia e Mercosul. Rio de Janeiro: ENSP/FIOCRUZ/MS, 2007. 365 p. Tese (Doutorado). Programa de Pós-Graduação em Saúde Pública, Escola Nacional de Saúde Pública Sergio Arouca, 2007. Disponível em: http://www.arca.fiocruz.br/bitstream/icict/4496/2/289.pdf. Acesso em: 26 dez. 2016.

UNIÃO EUROPEIA. Regulamento (CE) N. 883/2004 do Parlamento Europeu e do Conselho de 29 de Abril de 2004 relativo à coordenação dos sistemas de segurança social (Texto relevante para efeitos do EEE e para a Suíça). Disponível em: http: / /eur-lex.europa.eu/legal-

content/PT/TXT/PDF/?uri=CELEX:02004R0883-20140101\&from=PT. Acesso em: 23 dez. 2016.

UNIÃO EUROPEIA. Regulamento (CE) n. 987/2009 do Parlamento Europeu e do Conselho de 16 de Setembro de 2009 que estabelece as modalidades de aplicação do Regulamento (CE) n. 883/2004 relativo à coordenação dos sistemas de segurança social (Texto relevante para efeitos do EEE e a Suíça). Disponível em: http://eur-lex.europa.eu/legal-

content/PT/TXT/PDF/?uri=CELEX:32009R0987\&from=PT. Acesso em: 23 dez. 2016.

UNIÃO EUROPEIA. Directiva 2011/24/UE do Parlamento Europeu e do Conselho de 09 de março de 2011 relativa ao exercício do direito dos doentes em matéria de cuidados de saúde transfronteiriços. Disponível em: http://eur-lex.europa.eu/legalcontent/PT/TXT/PDF/?uri=CELEX:32011L0024\&from=PT. Acesso em: 23 dez. 2016.

Recebido em: 27/01/2017 / Revisões requeridas em: 10/04/2017 / Aprovado em: 08/05/2017 